Научная статья

УДК 130.2

DOI: $10.18101 / 1994-0866-2021-3-36-46$

\title{
ПРОСТРАНСТВЕННО-ВРЕМЕННОЙ КОНТИНУУМ В ПОСТМОДЕРНИСТСКОЙ ПАРАДИГМЕ: Ж. ДЕРРИДА (1930-2004)
}

\section{() Сироткин Юрий Львович}

кандидат социологических наук, доцент, Казанский юридический институт МВД России Россия, 420108, г. Казань, ул. Магистральная, 35 syurij75@gmail.com

\begin{abstract}
Аннотация. В статье рассматриваются оригинальные представления о пространстве - времени и их соотношении. Аналитика времени - пространства в творческом наследии Ж. Деррида инкорпорирована в общий контент представлений о пространственно-временном континууме в постмодернистском дискурсе. Раскрывается своеобразие анализа времени - пространства в постнеклассической парадигме гуманитарного знания (отказ от оппозиции конечное - бесконечное, рассеивания пространства, устранение причинности, словесный дискурс как история смысла, доминанта настоящего, преодоление социальности, разнообразие конструкций восприятия пространства - времени, их антропологическая природа, категоризация приватного пространства).

Показывается, что Деррида исходит из утверждения об отсутствии объективного времени и его существовании в потоке сознания, что свидетельствует об антропологической природе времени. Основополагающим является тезис о внутренне осознаваемом времени. Антропологизм времени - пространства предполагает доминанту настоящего. В настоящем происходит жизнь человека; оно находится в его сознании. Жизнь в настоящем есть присутствие. Констатируется динамика и обнаруживается структура настоящего. Обозначается своеобразие трактовки соотношения времени - пространства, в котором время поглощает пространство. Тем не менее обнаруживается множественность переходов пространства во время и времени в пространство. Относительно пространства обращается внимание на суждение о пространстве как действии мысли и языка. Текст соответствует представлениям о пространстве.

Раскрывается определение времени - пространства через отпечаток (след). След предстает во времени становления и пространстве различения. Попытка добиться определенности в описании пространственно-временных конструктов достигается Деррида обоснованием понятия «различАние», смысл которого переносится на характеристику пространственно-временного континуума. Констатируется, что след, различение, письмо, наличие являются узлами сочлененности и становятся средством постижения времени и пространства. Подчеркивается, что опыт обретения пространства - времени начинается с письма различия как материала следа. Понятийный ряд обогащается понятием предвосхищения - удержания; приоритет остается за предвосхищением как попыткой сохранить время в качестве основоположной пассивности. Пассивность следа конституируется в отношении времени при сомнении в адекватности описания структуры следа.
\end{abstract}


Ю. Л. Сироткин. Пространственно-временной континуум в постмодернистской парадигме: Ж. Деррида (1930-2004)

Ключевые слова: время, пространство, самоотношение, различение, различАние, след, письмо, наличие.

\section{Для цитирования}

Сироткин Ю. Л. Пространственно-временной континуум в постмодернистской парадигме: Ж. Деррида (1930-2004) // Вестник Бурятского государственного университета. Философия. 2021. Вып. 3. С. 36-46.

Своеобразие восприятия и анализа времени - пространства в постмодернистской парадигме заключается в акцентизации доселе периферийных концептов аналитики пространственно-временного континуума.

Многомерность пространства - времени обусловлена попыткой отказа от оппозиции конечное - бесконечное, что повлекло за собой утрату длительностью значения смыслообразования. Ацентризм как признак постмодернистского дискурса лишил возможности восприятия человеком пространства как системы мест; отношения между людьми в пространстве превратились в функцию (Ж. Бодрийяр). Детерриторизация пространства, т. е. его рассеивание как распределение сингулярностей, способствовала обретению признаков подвижности и способности к самовоссоединению (Ж. Делез, Ф. Гваттари). Понятия Эон и Хронос приобретают эпистемологическую нагрузку. В этом контексте выделяются два времени: первое состоит из настоящих, второе объединяет прошлое и будущее. Первое циклично. Второе линейно. Специфичны события. Бестелесные события Эона соответствуют отрезку в Хроносе. События Эона обладают вечной истиной. Хронос заполняется движением вещей и расположением тел. Хронос объективное время. Эон - астрономическое время (Ж. Делез).

Принудительная причинность утрачивает действенную силу. Время обретает бесконечную вариативность протекания. «Архив» как понятие приобретает значение маркера времени, кромка которого окружает настоящее (М. Фуко). Непрерывность прошлого утрачивается. В настоящем прошлое фрагментируется. Так устанавливаются пределы.

Линейная модель времени сменяется цикличной, что расширяет возможности событийной интерпретации. После времени разворачивается постистория. Ввиду переплетенности событий и их нелинейности исключается сколь-нибудь целостный исторический концепт. Рациональное постижение бытийности оказывается сомнительным. Сюжет истории предлагает нарратор, а историческое время мыслится в пространстве словесного дискурса. История оказывается историей смысла, который транслируется поколениями.

Постмодернистская эпистемологическая конструкция предполагает доминанту настоящего в восприятии человеком времени, так как настоящее концентрирует прошлое и содержит контуры будущего. Специфичен анализ времени пространства человеком «индивидуализированного общества» (3. Бауман) или «общества риска» (У. Бек). Индивидуализация как способ преодоления социальности актуализирует антропологический подход к пространству - времени. Возрастает значение частного восприятия, вращения событий вокруг собственного «я». Коллективные действия утрачивают прежнее значение. Восприятие согласовывается с саморазвитием индивида и поведенческой моделью. Индиви- 
дуализация и дифференциация обеспечивают разнообразие конструкций восприятия пространства - времени. Скорость преодоления пространства становится символом эпохи и фактором сохранения времени. Ключевыми понятиями аналитики пространства - времени оказываются восприятие и оценивание как антропологические феномены. Воспроизводится социальный контекст восприятия пространства - времени; оно становится дифференцированным в зависимости от социального статуса и изживается как предел (3. Бауман). Причем природа власти над временем и пространством отождествляется (П. Бурдье).

На этом фоне личное пространство расширяет пределы роста и поглощает социальное пространство. Происходит категоризация приватного пространства (Ю. Л. Сироткин). В изложенном контексте управление настоящим становится задачей каждого индивида (3. Бауман), что представляется непростым делом в виду фрагментарности, затрудняющим его рефлексию и аналитику. Фрагментарность и размытость предопределяют отдаленность настоящего как от прошлого, так и от будущего, которое вероятностно, поливариантно и не поддается предвидению. Сознание человека переносит риски в будущее и игнорирует их угрозы в настоящем, так как прошлое теряет способность определять будущее.

Таким образом, время и пространство сохраняют в постмодернистской парадигме континуальность своих проявлений. Эпизоды/фрагменты времени выступают в качестве свойств его восприятия человеком постмодерна, который становится субъектом антропологического времени.

В развернутой аналитической парадигме Деррида занимает оригинальное место. Творческое наследие французского философа обширно, оригинально необычностью интерпретаций и еще долго будет привлекать исследователей образностью языковых средств, своеобразными конструкциями текстов, парадоксальностью идей и многообразием дискурсов. Интерес к логическим построениям философа возрос на рубеже XX-XXI вв. и продолжает сохраняться, расширяя аналитические пределы. Российские исследователи находятся отнюдь не на периферии профессионального интереса к творческим изысканиям Деррида. В российской библиографике работ о Деррида мы встречаемся с разнообразием тематических векторов. Преимущественно анализируется проблематика знака и текста: неконтролируемости значения знака [15], функционирования языка [16], значения филологии в философском наследии Деррида [19], философский язык [2], двойственность философских текстов и этики деконструкции [5] и т. д. Исследуется проблема интерпретации в деконструктивизме Деррида [4], выявляется своеобразие интерпретации идей Ницше у Деррида [10], проблематика неклассической онтологии [13] и игры в фолософско-эстетической концепции Деррида [18], маргинализации дискурса [17], онтологического толкования феномена Следа в философских построениях Деррида [14], субъекта в творчестве Деррида [12] и т. д. Деррида представлен как основатель теории деконструктивизма [3]. Предложен анализ концептуальных представлений о языке Гуссерля и Деррида [11] и т. д.

Полнота библиографического обзора требует отметить, что исследовательский интерес к творчеству Деррида не ограничивается российской ойкуменой $[20$, 21,22 и т. д.]. 
Ю. Л. Сироткин. Пространственно-временной континуум в постмодернистской парадигме: Ж. Деррида (1930-2004)

Как видим, интерес российских интеллектуалов к творческому наследию Деррида глубок и устойчив, что соответствует тому значению, которое имеет корпус его работ для отечественных философов постнеклассической формации. Вместе с тем оказалась не затронутой проблема аналитики пространства - времени, которую Деррида осуществил в векторе постнеклассического дискурса с присущими ему парадоксами и недоговоренностями. На первый взгляд может показаться, что затрагиваемая проблематика периферийна для философских работ Деррида. Однако первое впечатление, как это нередко бывает, обманчиво потому, что оказывается поверхностным, ибо не учитывает языковое и терминологическое своеобразие изложения Деррида вечной проблемы пространственновременного континуума, осознанной им в рамках обозначенной концептуальной модели. Автор статьи предложил собственное видение времени - пространства в творческом наследии Ж. Деррида.

Ж. Деррида, как и Ж. Делез, несмотря на многочисленность сочинений, не имеет отдельной работы, посвященной пространству — времени. Тем не менее его рассуждения и замечания, разбросанные по различным произведениям и касающиеся пространственно-временного континуума, оригинальны и ценны.

Истоки аналитики пространства - времени у Деррида восходят к Ф. Ницше и Э. Гуссерлю. Философ обосновывает по меньшей мере два исходных тезиса, определяющих его понимание феномена. Первый звучит как утверждение о том, что нет объективного времени; оно существует в потоке сознания. Время антропологично по своей природе и сущности. Деррида убежден, что временная длительность не имеет объективного основания; она сугубо субъективна, причем обращена к восприятию другого как самого себя и самого себя как другого [6, c. 561-562].

Второй тезис гласит. Своеобразие восприятия времени заключается в том, что вначале человек воспринимает себя, а через себя время. Иными словами, время пребывает в человеке и воспринимается им как внутреннее, осознаваемое время. Причем внутреннее время присуще всем живым системам в независимости от продолжительности жизни (от комара -1 час до кошки - 13 лет). Дело здесь в отличительных признаках восприятия, имеющих процессуальносодержательный характер; самовосприятие человека распространяется до факта собственной кончины. В этом смысле смерть становится самовосприятием жизни, а жизнь самовосприятием смерти [6, с. 562]. Это человеческое восприятие жизни, которая является весьма редкой разновидностью смерти (Ф. Ницше). В данном контексте позиции Деррида и Ницше близки, что собственно трудно не заметить и обойти вниманием.

В настоящем изложении не требует широкой аргументации обосновываемый нами тезис о том, что проблематика времени - пространства в постмодернистской парадигме антропологична по природе, сущности и генезису. Деррида лишний раз подтверждает этот базовый тезис, определяя опыт пространственновременного континуума исходя из общего основания субъектности и культуры в их доэмпирическом бытии, разнообразие которого определяется разнообразием их ориентаций как собственных пространственно-временных организаций [8, 
c. 480]. Антропологизм пространства - времени предполагает доминанту настоящего. В настоящем разворачивается жизнь человека.

Жизнь зарождается и проходит в настоящем. Настоящее находится в сознании человека. Поэтому настоящее воспринимается. Настоящее определяет значение человека для жизни как жизни в настоящем, которая находится в себе, а не вне субъектности, т. е. во времени и пространстве. Жизнь в настоящем есть бытие присутствия или его модификация [7, с. 57-58; с. 74].

Время обозначает движение, которое понимается в терминах настоящего. Взгляды Деррида на настоящее созвучны рассуждениям Гуссерля, в которых утверждается господство настоящего и отвергается «после-бытие».

Так как время антропологично, его субъектом является человек. Настоящее как Теперь обладает сложной динамикой и неоднозначной структурой. Другое Теперь выступает необходимым транзитом времени для меня. Живое Теперь порождается спонтанно. Это хаотичный и весьма своеобразный процесс. Процессуальность порождает Теперь, которое должно удерживаться в другом Теперь, чтобы быть Теперь. Порождающий Теперь процесс протекает в условиях самовоспроизведения, без вмешательства извне, в том числе и эмпирического. Новая первичная актуальность преобразует Теперь в не-Теперь, т. е. в прошлое Теперь. Такой процесс обозначается Деррида как самоотношение. В нем процесс идентификации (того же самого с Тем же самым) осуществляется только через восприятие другого. В результате другое становится другим Того же самого. Такому соотношению требуется чистота, поскольку на первичное восприятие ничто не воздействует. Иначе говоря, это самовосприятие, очищенное от внешних влияний. Однако в качестве осуществляющего влияние все же остается другое первичное восприятие, которому свойственна новизна и которое становится другим Теперь [7, с. 111-113].

В метафизике, считает Деррида, господствует метафоричность обозначения времени, которая одновременно обнажает и ретуширует эволюцию обозначенного соотношения. Предложенное обобщение весьма категорично: «время» - это метафора, которая в одно и то же время (курсив Деррида] показывает и скрывает «движение» этого соотношения» [7, с. 113].

Своеобразно трактуется соотношение времени - пространства. Время поглощает пространство. Пространство становится жизнью во времени и приобретает качество самоотношения времени. Это нечто внешнее раскрывается как внешность пространства или пространство внешности, которое оказывается вне времени, но обретается как движение темпоризации внутри внешнего [7, с. 114].

У Деррида пространственно-временные координаты теряют устойчивость, что приводит к иным возможностям соотнесения. Соотнесенность обнаруживает множественные переходы пространства во время и наоборот. Внутреннее пространство оказывается представляемым. Нынешние модели обоснования знания исходят из методичного, нередко спонтанного, но беспрерывного возведения здания обозначаемого и дополнения смыслами обозначающих предметы понятий (по словам Н. С. Автономовой, «постоянного достраивания и доращивания образов предметов» [1, с. 78]), что приводит к парадоксам движения, одновременно включающее приближение и отдаление. Пространство превращается в действие 
Ю. Л. Сироткин. Пространственно-временной континуум в постмодернистской парадигме: Ж. Деррида (1930-2004)

мысли и языка. В нем все уравнивается: начало и конец, центр и периферия. Соответствует определенным представлениям о пространстве и текст. В тексте равнозначны, с одной стороны архаика и фольклор, с другой - постсовременность и гипертекст. Такое повествование не имеет ни конца, ни начала, в нем отсутствует центр и периферия, смыслы неопределенны также как и выражающие их понятия. Все находится в безграничном круговороте, где потоки сознания пересекаются, образуя необыкновенную вязь, в которой блуждающее сознание тщетно пытается обрести смысл. (Схожая, но более метафорическая аналитика обнаруживается и у других авторов, в частности, у Н. С. Автономовой [1, с. 78]). Заимствуя метафоричность изложения, скажем, что пространство становится лоскутным одеялом, на площади которого каждый лоскуток автономен, оригинален и самоценен. Они не образуют мозаичного полотна; их совокупность вне сюжета; они равно самодостаточны, как и ущербны.

Бытие как присутствие, после ряда превращений, определенных как «повторение, уходящее в бесконечность», приобретает значение, выраженное понятием «живое настоящее», структура которого не содержит ни субъекта, ни атрибута, что является фундаментальным основанием феноменологии метафизики [см.: 7, с. 131]. Присутствующее от того, что им не является, отделено интервалом. Интервал и присутствующее взаимозависимы. Такой интервал неустойчив; он объединяется и разделяется одновременно. Происходит оформление пространства, по терминологии Деррида «опространствление», т. е. становление как пространством времени, так и временем пространства [7, с 184].

Согласно Деррида это есть различение. Различение обретает смысл в том, что делает движение возможным при условии, если присутствующее, явившееся на сцену присутствия, обладает способностью к соотносимости. Оно, т. е. присутствующее, соотносится со всем, что не является им самим; сохраняет в себе метку прошлого и обретает своеобразие соотношений с элементами будущего. Но и в этом случае след соотношения с будущим коррелирует с соотношением с прошлым. Так конституируется присутствующее. Конституирование присутствующего происходит через отношение к неприсутствующему, которое не содержит ни прошлого, ни будущего как результата модификации присутствующего [7, c. 183-184].

Обращение Деррида к следу (прото-следу) конституирует антропологическое пространство - время и оказывается средством его постижения. Время располагается между прошлым и будущим, а растягивается опытом «удержания» прошлого и «предвосхищения» будущего. Примечательно, что опыт развертывается постепенно и приобретается не в настоящем, а в будущем, обращенном в прошлое. Призвание настоящего заключается в сохранении прошлого и предначертании будущего. Обоснованной является попытка Деррида определить время пространство через отпечаток (след). Аргументация выглядит следующим образом. Различия проявляются в элементах, их строении, конфигурациях и т. д. Допускается, что различия порождают элементы, из которых рождаются тексты и в определенной последовательности образуются цепочки следов. Цепочки системы просматриваются лишь в конструкции следа или отпечатка. Различия обнаруживаются в своеобразной области отпечатка и следа или в овремененном пережива- 
нии, которое не бытийствует ни в одном из миров, являясь равно аудиальным и визуальным, предстающем равно во времени, и в пространстве [8, с. 191].

След являет частицу времени становления и пространства расчленения. Она соотносится с прошлым, настоящим и будущим. Эта соотнесенность названа «восполнением»: неполнота стремится преодолеть себя, но никогда не достигнет полноты; балансирует между заполняемостью и изъятием в равных пропорциях. Наличие образует бесконечноть и растворяется во множестве следов. Бесконечность децентрирована и деиерархизирована. В этом случае доминирует логика несамотождественного восполнительства, побуждаемая потребностью - воображением.

Попытка достичь определенности в весьма противоречивых описаниях пространственно-временного континуума приводит Деррида к обоснованию весьма уязвимого понятия «различАние». Последуем тем не менее в рассуждениях вслед за философом. «РазличАние» раскрывается как условие означения, как основа оппозиции наличия - отсутствия, основа жизни. РазличАние обозначает явление, которое оттягивает время и является промежутком пространства. Единство данного места и настоящего момента обозначает наличие. РазличАние разбивает единство: время обретает замедленность, а пространство отстраненность. Промедление и отстранение суть деформации, которые взаимодействуют. Семантика слова различАние переносится на характеристику пространственно-временного континуума. Взаимосоотнесенное становление времени и пространства трактуется как становление временем пространства и становление пространством времени (Э. Гуссерль). Деррида стремится к отстранению, отсрочиванию всего в человеческом мире, в том числе времени и пространства.

След, различение, письмо - это узлы — сочленения пространства — времени. Феноменологическая природа следа и письма не означает снятия сорасчлененности пространства и времени, не препятствует взаимопревращению одного в другое. Это означает сохранение временного становления пространства и пространственного становления времени. Традиционное понятие времени и организация пространства связывается с линейным письмом. Техника письма оформила социальное пространство. Письмо как движение предопределило линейность времени. Деррида неоднократно обыгрывает мысль, что наше пространство время - это пространство - время следа.

К перечисленным узлам не будет преувеличением добавить наличие. Деррида неоднократно повторяет мысль: наличие является основой осмысления времени и отменяет обратную зависимость: осмысления наличия на основе времени, что определяет время как различАние [см.: 8, с. 321, 428, 504 и т. д.]. Завершаются размышления формулировкой закономерности: «Чем больше мы углубляемся во времени утраченного наличия, тем ближе к нам его обретенное время» [8, с. 486]. Наличие - абстракция Деррида - есть способ бытия всего как в онтологическом, так и в антропологическом смысле. Обладая рядом характеристик (полнотой, самотождественностью и т. д.), эта абстракция выражает настоящее как вечно присутствующее, т. е. «здесь и теперь». Иными словами, наличие выражает единство «здесь и теперь», настоящего времени и конкретного пространства. Напомним с целью сохранения логики восприятия излагаемого, что след обозна- 
Ю. Л. Сироткин. Пространственно-временной континуум в постмодернистской парадигме: Ж. Деррида (1930-2004)

чает картину мира, где нет «здесь и теперь». След предшествует мыслям о сущем и неуловим в простоте настоящего. Различие как противоположность наличию в смысле тождества и самодостаточности дополняется различАнием. РазличАние - это запаздывание времени, его отсроченность. Единство различия разбивается различАнием - временной аспект промедляется; пространственный разбивается. После напоминаний вовсе необоснованных принятой логикой изложения, но необходимых в силу ее своеобразия, вернемся к обоснованию тезиса Деррид о том, что время и пространство воспринимаются посредством письма (прото-письма) и следа. Опыт обретения пространства - времени начинается с письма различия как материала следа. Он способствует обнаружению формообразования внутри пространственно-временного континуума, результатом чего является расчленения опыта как единства, который переживается как самотождественность [8, c. 192].

Восприятие и переживание пассивно. Своеобразие трактовки пассивности отсылает нас к отношению к прошлому, которое всегда с нами, но которое не представляется возможным быть оживленным (перво)началом. Невозможность отыскания «живой очевидности первоналичия» направляет вектор ориентации на «абсолютное прошлое», что предоставляет возможность определить след как «налично-настоящее (present)» [8, с. 193].

В соотношении предвосхищение (protention) — удержание (retention) приоритет отдается предвосхищению. В этом случае повышается риск исчезновения неразложимого и находящегося, а значит и времени, которое выступает в качестве основоположной пассивности. След содержит в себе указание на абсолютное прошлое и обязательства по его осмыслению как настоящего, которое, изменившись, становится прошлым (unpresentpasse). Настоящее проходит, превращаясь в прошлое. Абсолютное прошлое сохраняется в следе и не дает оснований для определения его как «прошлого» [8, с. 194]. Такова констатация Деррид.

Пассивность следа манифестируется как в отношении прошлого, так и будущего. Поэтому описание структуры времени, сколь-нибудь приближенном к адекватности с помощью понятий времени (прошлое, настоящее, будущее), не представляется возможным. Иначе говоря, усложняемая структура времени (например, что настоящее, отошедшее в прошлое (presentpasse), настоящее, перекидываемое в будущее (presentfutur) ) не дает эпистемологических девидендов. Словами «разбивка», в прото-письмо означается «сорасчленность пространства и времени», т. е. то, что ранее было обозначено как становление пространства временем и временем пространства [8, с. 196]. Читатель недоумевает: зачем Деррида понадобилось вводить столько метафорических понятий, если с их помощью не удается углубиться в объяснение времени? То же недоумение адресуется «разбивке» как прото-письму. Прото-письмо (разбивка) фиксирует момент «мертвого времени в наличии живого настоящего, в общей форме всякого наличия. Это безвременье (letempsmort)» [8, с. 196]. Неопределенность суждения о предмете разговора сводится к неопределенности терминологических обозначений и дефицита языковых средств, для выражения мыслей как «потока сознания». Но какова тогда цель знания, если не в понятийной определенности предмета исследовательского интереса? В обсуждении того, что непостижимо и недоступно зна- 
нию? Или это обсуждение ради обсуждения того, чего нет и не может быть? Но это не относится ко времени - пространству, феномен которого имеет объектсубъектную природу. Это не относится и к гуманитарному знанию в целом, так как требования сциентизации гуманитарного мышления - точность, логичность и последовательность - никто не отменял [9].

Тем не менее заслуга Деррид видится в предложенном характере обсуждения феномена, который вызывает интерес своей необычностью и порождает фантазии на тему пространства - времени.

\section{Литература}

1. Автономова Н. С. Деррида и грамматология // Жак Деррида о грамматологии / перевод с французского и вступительная статья Н. Автономовой. Москва: AdMarginem, 2000. С. 7-107. Текст: непосредственный.

2. Автономова Н. С. Философский язык Жака Даррида. Москва: РООССПЭН. 2011. 509 с. Текст: непосредственный.

3. Аганбекова У. Р. Жак Деррида как основатель теории деконструктивизма // Балканское научное обозрение. 2018. № 1. С. 5-7. Текст: непосредственный.

4. Беляева А. М. Проблема интерпретации в деконструктивизме Ж. Деррида и его последователей: автореферат диссертации на соискание ученой степени кандидата философских наук. Москва, 2008. 23 с. Текст: непосредственный.

5. Вдовина А. В. Жак Деррида о двойственности философских текстов и этике деконструкции // Дискуссия. 2012. № 1. С. 12-14. Текст: непосредственный.

6. Деррида Ж. Страсти по Фрейду // О почтовой открытке от Сократа до Фрейда и не только / перевод с французского Г. А. Михалкович. Минск: Современный литератор, 1999. С. 401-644. Текст: непосредственный.

7. Деррида Ж. Голос и феномен и другие работы по теории знака Гуссерля / перевод с французского С. Г. Кашиной, Н. В. Суслова. Санкт-Петербург: Алетейя, 1999. 208 с. Текст: непосредственный.

8. Деррида Ж. О грамматологии / перевод с французского и вступительная статья Н. Автономовой. Москва: AdMarginem, 2000. 511 с. Текст: непосредственный.

9. Золотухина-Аболина Е. В. Алгоритм и свобода: к вопросу о судьбах гуманитарной культуры // Вопросы философии. 2019. № 9. С. 32-39. Текст: непосредственный.

10. Игнатенко А. С. Интерпретация идей Фридриха Ницше во французской философии второй половины XX века: Фуко, Делез, Деррида: автореферат диссертации на соискание ученой степени кандидата философских наук. Москва, 2008. 23 с. Текст: непосредственный.

11. Леденева Е. В. Конституирование и деконструкция: сравнительный анализ концепций языка Гуссерля и Даррида: диссертация на соискание ученой степени кандидата философских наук. Москва, 2003. 139 с. Текст: непосредственный.

12. Мазин В. А. Субъект Фрейда и Деррида. Санкт-Петербург: Алетейя, 2010. 255 с. Текст: непосредственный.

13. Нестерова М. В. Неклассическая онтология французского постмодернизма: концепция Жака Деррида: диссертация на соискание ученой степени кандидата философских наук. Хабаровск, 2006. 181 с. Текст: непосредственный.

14. Политов А. В. Феномен следа в философии Жака Деррида и его онтологическое истолкование // Вестник Пермского национального исследовательского политехнического университета. Культура, история, философия, право. 2016. № 4. С. 93-102. Текст: непосредственный. 
Ю. Л. Сироткин. Пространственно-временной континуум в постмодернистской парадигме: Ж. Деррида (1930-2004)

15. Сахневич С. В. Тезис Ж. Деррида о неконтролируемости значения знака как основания для клиентоориентированного перевода // Вестник Тверского государственного университета. Сер.: Филология. 2014. № 4. С. 271-275. Текст: непосредственный.

16. Смирнов В. В. Ж. Деррида и Л. Витгенштейн о проблеме функционирования языка // Вестник Тверского государственного университета. Сер.: Философия. 2011. № 2. С. 53-61. Текст: непосредственный.

17. Соколов Б. Г. Маргинальный дискурс Деррида. Санкт-Петербург, 1996. 119 с. Текст: непосредственный.

18. Шестакова Е. А. Проблема игры в философско-эстетической концепции Жака Деррида: диссертация на соискание ученой степени кандидата философских наук. Москва, 1997. 144 с. Текст: непосредственный.

19. Юнусова И. Ш. Жак Деррида как филологический философ // Актуальные проблемы теоретической и прикладной филологии: материалы VI Международной конференции для молодых ученых / ответственный редактор А. Р. Мухтаруллина. Уфа: Изд-во Башкир. гос. ун-та. 2018. С. 279-283. Текст: непосредственный.

20. Burk Sean. The death and return of the autor: criticism and subjectivity in Barthes, Foucault and Derrida. 3d ed. Edinburgh: Edinburgh univ. press, 2008. 283 p. Текст: непосредственный.

21. Geimer P. Derrida ist nicht zu Haus: Begegnungen mit Adweseden/Peter Geimer; mit einem Nachw. Von Marsel Beyer. Hamburg: Philo Fine Arts, cop. 2013. 256 p.

22. Wigley M. Architector und Deconstruktion: Derrida Phantom. Basel (etc.): Birkhauser, cop. $1994.174 \mathrm{p}$.

Статья поступила в редакцию 10.06.2021; одобрена после рецензирования 05.07.2021; принята к публикации 14.07.2021.

\section{SPACE-TIME CONTINUUM IN THE POST-MODERN PARADIGM: J. DERRIDA (1930-2004)}

\section{Yury L. Sirotkin}

Cand. Sci. (Sociol.), A/Prof.

Kazan Law Institute of the Ministry of Internal Affairs of Russia

35 Magistralnaya St., Kazan 420108, Russia

syurij75@gmail.com

Abstract. The article deals with the original ideas about space-time and their correlation. Analytics of time-space in the legacy of J. Derrida is incorporated into the general content of ideas about space-time continuum in the postmodern discourse. We note the uniqueness of time-space analysis in the post-non-classical paradigm of humanitarian knowledge (rejection of the finite-infinite opposition, dispersion of space, elimination of causality, verbal discourse as a history of meaning, dominance of the present, overcoming sociality, a variety of structures of space-time perception, their anthropological nature, categorization of the private space).

J. Derrida proceeds from the statement about the absence of objective time and its existence in the stream of consciousness, this suggests that time has the anthropological nature. The fundamental thesis is about the consciousness of internal time. Anthropologism of time-space presupposes dominance of the present. Human life takes place in the present, it is in his mind. Life in the present is presence. We consider the dynamics and the structure of the present, the interpretation of correlation between time and space, in which time folds 
space. Nevertheless, there is a multiplicity of transitions of space in time and time into space. We pay attention to the judgment about space as an action of thought and language. The text corresponds to the concept of space.

We discuss the definition of time-space through an imprint (a trace). A trace appears in the time of becoming and the space of difference. An attempt to achieve certainty in the description of space-time constructs is achieved by Derrida by substantiating the concept of "différance", which meaning is transferred to the characteristics of the space-time continuum. Trace, difference, writing, presence are nodes of articulation and become a means of comprehending time and space. It is emphasized that the experience of gaining space-time begins with the writing of difference as a material of the trace. The conceptual construct is enriched with the concept of anticipation-retention; anticipation is in priority as an attempt to preserve time as a fundamental passivity. The passivity of a trace is constituted in relation to time when there is doubt about the adequacy of the description of the trace structure. Keywords: time, space, self-attitude, difference, différance, trace, writing, presence

For citation

Sirotkin Yu. L. Space-Time Continuum in the Post-Modern Paradigm: J. Derrida (19302004). Bulletin of Buryat State University. Philosophy. 2021; 3: 36-46 (In Russ.).

The article was submitted 10.06.2021; approved after reviewing 05.07.2021; accepted for publication 14.07.2021. 